\title{
Caveolins as Regulators of Stress Adaptation
}

\author{
Jan M. Schilling, Brian P. Head, and Hemal H. Patel \\ Veterans Administration San Diego Healthcare System and Department of Anesthesiology, UCSD School of Medicine, San \\ Diego, California
}

Received November 27, 2017; accepted January 19, 2018

\section{ABSTRACT}

Caveolins have been recognized over the past few decades as key regulators of cell physiology. They are ubiquitously expressed and regulate a number of processes that ultimately impact efficiency of cellular processes. Though not critical to life, they are central to stress adaptation in a number of organs. The following review will focus specifically on the role of caveolin in stress adaptation in the heart, brain, and eye, three organs that are susceptible to acute and chronic stress and that show as well declining function with age. In addition, we consider some novel molecular mechanisms that may account for this stress adaptation and also offer potential to drive the future of caveolin research.

\section{Introduction}

Caveolins (Cav) are ubiquitously expressed proteins found in many cell types and have been abundantly studied as major regulators of cell function and physiology. As form follows function, the initial discovery and description was limited to structural characterization of caveolae, Latin for "little caves," first identified in the early 1950s by Palade (1953) and Yamada (1955) using electron microscopy. Though initially considered artifacts of tissue processing for electron microscopy, in the nearly four decades following the initial discovery of the caveolar structure to eventual molecular characterization, multiple studies have described the physical presence of caveolae in numerous cell types and organ systems (Mugnaini et al., 1977; Gabella, 1978; Costello and Shafiq, 1979; Abrahams et al., 1980; Frank et al., 1980; Oguchi and Tsukagoshi, 1980; Severs, 1981; Sakata et al., 1983) and manipulation of the structure through a number of interventions (i.e., swelling, osmotic stress, stretch) (Gabella and Blundell, 1978; Sage and Jennings, 1988; Kordylewski et al., 1993; Parton et al., 1994). What emerged from these largely structural electron microscopy studies was the sense that caveolae were dynamic and versatile structures that could be manipulated by extracellular stressors. In the early 1990s, the protein caveolin, the structural and scaffolding component of

This work was supported by grants from National Institutes of Health [HL091071, HL107200, HL066941, AG052722] and the Department of Veterans Affairs [BX001963, BX003671].

https://doi.org/10.1124/mol.117.111237. caveolae, was discovered (Rothberg et al., 1992) and this allowed over the next two decades the molecular characterization of structural caveolae. Caveolins served as a means to explain compartmentation of signaling molecules that could be assembled into these "little caves" via enrichment of caveolins and various lipids creating a microenvironment for efficient signaling.

Besides the discovery of caveolin proteins, the one tool that has most dramatically shaped and guided caveolin research is the generation of caveolin knockout mice (Galbiati et al., 2001; Razani et al., 2001, 2002; Park et al., 2002b). Three isoforms of caveolin have been identified, with caveolins -1 and -2 being ubiquitously expressed and caveolin-3 being restricted predominantly to muscle (Williams and Lisanti, 2004). Though the various caveolin knockout mice showed a number of phenotypes (i.e., altered life span, muscular dystrophy, cardiomyopathy, altered adiposity, pulmonary hypertension, neoplasia, etc. (Galbiati et al., 2001; Razani et al., 2001, 2002; Park et al., 2002a,b, 2003; Woodman et al., 2002; Williams and Lisanti, 2004; Capozza et al., 2005)), knockout of one or effectively all caveolins did not result in lethality. Such an observation questions the relative importance and central focus that has been attributed to caveolin as a key regulator of such critical and important cellular functions; compatibility with life of the various single- and doubleknockout mice would suggest some sort of potential compensation (Insel and Patel, 2007). Interestingly, restoring Cav-1 specifically in the endothelium of Cav-1 global knockout mice restores many of the specific pathophysiologies observed in

ABBREVIATIONS: AC, adenylyl cyclase; Akt, protein kinase B; $\beta A R, \beta$-adrenergic receptor; BBB, blood-brain barrier; Cav, caveolins; eNOS, endothelial nitric oxide synthase; ERK, extracellular signal-regulated kinases; GPCR, G protein-coupled receptor; IPC, ischemic preconditioning; I/R, ischemia-reperfusion; KO, knockout; MAPK, mitogen-activated protein kinase; NMDAR, N-methyl-D-aspartate receptor; PI3K, phosphoinositide 3-kinase; PKA, protein kinase A; T, transverse; TrkB, tropomyosin receptor kinase B. 
the global Cav-1 knockout mouse (Murata et al., 2007). This suggests that cell-specific expression of caveolin as well as expression of caveolin in specific cells may be the feature most critical to organism health. Since the discovery of the caveolin proteins, over 6500 publications appear on PubMed with the term caveolin and nearly a sixth of these make some use of caveolin knockout phenotypes (i.e., knockout, deficient, null). A broad perspective on this literature suggests an alternative view of the importance of caveolin to biology: Loss of caveolin may not result in embryonic lethality; rather, its expression and ultimate manifestation in caveolae allows the cell, organ, and organism to sense and respond in an efficient manner to external stimuli and the larger environment for stress adaptation. What has emerged from this larger view is that, in general, increased expression of caveolin is adaptive to stress (i.e., survival positive), whereas loss of caveolin is maladaptive (i.e., survival negative) (Fig. 1). Though caveolin is ubiquitously expressed and has important implications for physiology, pathophysiology, and stress adaptation in multiple organs and various cell types (i.e., see the following thorough reviews for lung (Jin et al., 2011; Maniatis et al., 2012; Royce and Le Saux, 2014; Thompson et al., 2014) and liver (Fernandez-Rojo and Ramm, 2016), we will focus on three particular organs. If one were to age long enough with no other issues, three things would likely fail, the brain, heart, and eyes owing to declining function of terminally differentiated cells that largely make up these organs. As such, these become important organs for consideration of caveolin expression and stress adaptation as a function of age. This review will focus on the role of caveolin in the heart, brain, and eye in terms of stress adaptation and offer perspective on potential novel caveolin-dependent molecular determinants of this adaptation.

\section{Heart}

Terminal differentiation of cells offers a means to develop specialization of cells on the basis of structure, shape, and function with potential maintenance of the cell for a lifetime. In the heart, the cardiac myocyte serves this purpose. It is largely nondividing and therefore its survival is critical to stress adaptation. Stress in the heart can be described as acute, chronic, and building across a lifetime.

In terms of acute stress, Murry et al. (1986) discovered that multiple, brief episodes of ischemia, applied before a sustained ischemic insult, did not contribute to ischemic injury; rather, it induced an increased resistance to ischemic damage. Termed ischemic preconditioning (IPC), this intervention has proven to be the most robust and potent application to confer protection against myocardial ischemia/reperfusion (I/R) injury. Preconditioning is mediated via a molecular signaling cascade that has become known as the reperfusion injury salvage kinase pathway (Hausenloy et al., 2005). The role of caveolin in regulating IPC and the signaling network of survival kinases is well described. Ischemia/reperfusion injury activates p42/44 and p38 mitogen-activated protein kinases (MAPKs), redistributes Cav-3, and downregulates expression of Cav-1 (Ballard-Croft et al., 2006). Ischemic preconditioning may modulate the microenvironment of caveolae and caveolin-associated protein interactions so as to enrich for proteins that promote cardiac protection. This idea is consistent with findings indicating that endothelial nitricoxide synthase (eNOS) and the glucose transporter GLUT4 translocate to caveolae after preconditioning (Koneru et al., 2007). Myocytes treated with methyl- $\beta$-cyclodextrin to deplete membrane cholesterol and disrupt caveolae fail to display IPC and opioid-mediated cardiac protection (Patel et al., 2006), whereas transgenic mice with cardiac myocyte-specific overexpression of Cav-3 have increased tolerance to myocardial I/R injury. Hearts of Cav-3-overexpressing mice have an improved functional recovery after myocardial ischemia and reperfusion, and increased basal protein kinase B (Akt) and glycogen synthase kinase $3 \beta$ phosphorylation, suggesting augmentation of the reperfusion injury salvage kinase signaling pathway in Cav-3-overexpressing mice (Tsutsumi et al., 2008). Such findings suggest that caveolae/caveolins may be major regulatory control points for cardiac homeostasis and pathophysiology in the acute setting, predominantly by providing a scaffold for existing and trafficking proteins.

The protective role of caveolin in the setting of acute stress may be potentially ubiquitous. Caveolin is critical to

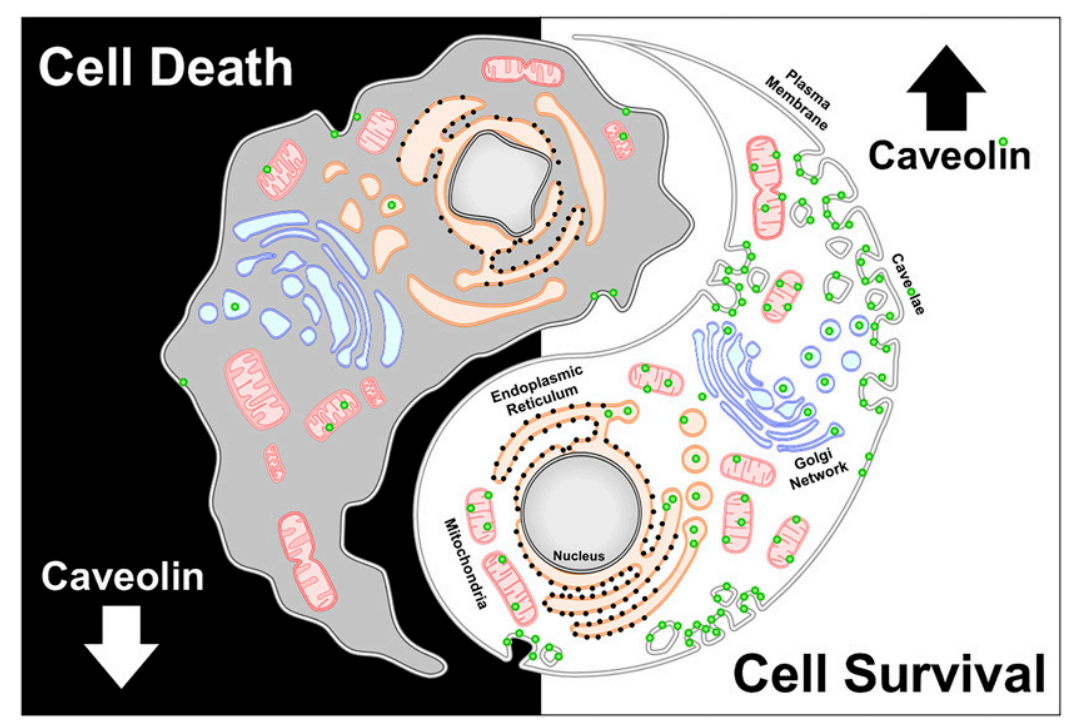

Fig. 1. Caveolin has a critical role in maintaining cell survival via regulation of multiple cellular sites, including the membrane and mitochondria, as well as negative aspects-loss of caveolin expression can lead to cell death. 
protection in the heart and kidney and may regulate common signaling pathways. Pharmacological agents such as volatile and intravenous anesthetics and opioids that have the potential to activate $G$ protein-coupled receptors (GPCRs) to induce acute protection in multiple organs may use caveolin as a key signaling protein in mediating this response (Patel et al., 2007; Horikawa et al., 2008; Song et al., 2010; Tsutsumi et al., 2010; See Hoe et al., 2014; Zhu et al., 2017). These agents appear to use caveolin and its binding partners to enhance signaling efficiency in these various organs, suggesting that a common network of cellular protection may be activated. Importantly, these agents also show the ability to modulate caveolin and caveolae, suggesting that potential pharmacological means to manipulate these proteins and structures may advance potential therapies in the future.

As stress becomes more chronic, the network of proteins and structures have added pressures that lead to modulation of expression of various proteins and signaling networks. Heart failure is a major cause of morbidity and mortality with very large human, social, and economic costs (Lloyd-Jones et al., 2009). The quality of life and life expectancy of patients with heart failure are poor despite optimal therapy.

Both Cav-1 and -3 have been shown to be involved in cardiac hypertrophy. Knockout of Cav-1 (Cav-1 KO) results in cardiac hypertrophy and induces contractile dysfunction (Augustus et al., 2008b). Hearts from Cav-1 KO mice show a progressive cardiac hypertrophy characterized by increased cardiomyocyte size and interstitial fibrosis. Impairment of heart function in Cav-1 KO mice is characterized by a dilated cardiomyopathy with an enlarged left ventricular diameter, wall thinning, decreased systolic function, and decreased contractility (Cohen et al., 2003). Although gross histologic and functional changes within the heart are a hallmark of Cav-1 depletion, Cav-1 KO mice exhibit hyperactivation of the p42/44 MAPK cascade in isolated cardiac fibroblasts (Cohen et al., 2003) and nitric oxide synthase in endothelial cells. It is known that caveolae contain numerous signaling molecules involved in cardiac hypertrophy, including but not limited to $\alpha$ adrenergic receptors, $\mathrm{G}_{\mathrm{q}}$ proteins, phospholipase $\mathrm{C}$, epidermal growth factor receptors, Ras, MAPKs, Src kinases, natriuretic peptide receptors, and Cav-3 (Krajewska and Masłowska, 2004). Woodman et al. (2002) have shown that knocking out the gene for Cav-3 results in hyperactivation of the Ras/extracellular signal-regulated kinases (ERK) 1/2 signaling pathway, cardiac hypertrophy, and reduced cardiac function. Cav-1/Cav-3 double KO mice completely lack morphologically identifiable caveolae and develop a severe cardiomyopathic phenotype with left ventricular hypertrophy and dilation (Park et al., 2002b). Cav-3 KO mice develop cardiomyopathy characterized by hypertrophy, ventricular dilation, and reduced contractility (Woodman et al., 2002). Koga et al. (2003) have demonstrated that in vitro overexpression of Cav-3 in neonatal cardiac myocytes attenuated phenylephrine- and endothelin-induced ERK1/2 activation and blocked myocyte hypertrophy. Cardiac-specific overexpression of caveolin results in blunted hypertrophy and cardiac dysfunction in response to transverse aortic constriction (Horikawa et al., 2011).

When considering the organization of signaling networks critical to heart failure, the adrenergic nervous system is a key part of the neurohumoral response to heart failure and a major focus of heart failure research and therapy (Triposkiadis et al., 2009). Decreased cardiac function in the early stages of heart failure leads to increased sympathetic neuronal activity, increased circulating norepinephrine, and activation of cardiac $\beta$-adrenergic receptors ( $\beta \mathrm{ARs}$ ) as a means to increase cardiac output by increasing heart rate and myocardial contractility. However, heart failure progression is associated with a decrease in $\beta_{1} \mathrm{AR}$ number and in coupling of $\beta_{1}$ and $\beta_{2} \mathrm{ARs}$ to downstream effectors (Dorn and Liggett, 2009). Persistent $\beta \mathrm{AR}$ stimulation worsens heart failure, and therapy with $\beta \mathrm{AR}$ agonists can be detrimental. $\beta \mathrm{AR}$ antagonists are now used to treat patients with heart failure. Deleterious effects of persistent $\beta \mathrm{AR}$ activation appear to result from activation of the $\beta_{1} \mathrm{AR}$ pathway, whereas beneficial effects from $\beta_{2} \mathrm{AR}$ activation may ameliorate such deleterious changes (Xiao et al., 2004). $\beta_{1} \mathrm{ARs}$ and $\beta_{2} \mathrm{ARs}$ are the principal $\beta \mathrm{ARs}$ in the heart, but $\beta_{3} \mathrm{ARs}$ may also contribute to cardiac $\beta \mathrm{AR}$ activity and may be a therapeutic target for heart failure. Work in recent years has shown that subcellular localization/ compartmentation of $\beta \mathrm{AR}$ subtypes within cardiac myocytes influences functional responses that result from receptor activation. Altered distribution of $\beta \mathrm{ARs}$ in cardiac myocytes may be a critical derangement in heart failure progression (Dorn, 2010; Nikolaev et al., 2010; Macdougall et al., 2012).

Recent data show that ideas about GPCR signaling must take into account subcellular localization of the receptors and postreceptor signaling components (Calebiro et al., 2009; Kamal et al., 2012; Maurice et al., 2012; Timofeyev et al., 2013). The localization of $\beta_{1} \mathrm{ARs}$ and $\beta_{2} \mathrm{ARs}$ differs in cardiac myocytes (Steinberg, 2004). $\beta_{1} \mathrm{AR}$ is broadly expressed in the sarcolemma, whereas $\beta_{2} \mathrm{AR}$ primarily localizes to caveolar microdomains. $\beta \mathrm{AR}$ subtypes in the different locales have different signaling properties: $\beta_{1} \mathrm{AR}$ activation produces inotropic and chronotropic responses via global $\mathrm{G}$ stimulatory $\left(\mathrm{G}_{\mathrm{s}}\right)$ coupling and activation of adenylyl cyclase (AC; AC 5 and 6 are the two major $\mathrm{AC}$ isoforms in the heart), protein kinase $\mathrm{A}$ (PKA), cAMP-regulated guanine nucleotide exchange factors (Epac), L-type calcium channels, and other downstream targets (Chen-Izu et al., 2000; Timme et al., 2000; Xiang and Kobilka, 2003; Han et al., 2013; Pereira et al., 2013). In contrast, $\beta_{2} \mathrm{ARs}$ couple to both $\mathrm{G}_{\mathrm{s}}$ and $\mathrm{G}$ inhibitory $\left(\mathrm{G}_{\mathrm{i}}\right)$ pathways. $\beta_{2} \mathrm{ARs}$ localized in caveolae produce transient PKA-dependent inotropic responses adjacent to L-type calcium channels, followed by decreased contraction owing to sequential coupling to $\mathrm{G}_{\mathrm{s}}$ and then $\mathrm{G}_{\mathrm{i}}$ proteins (Xiang and Kobilka, 2003). $G_{i}$ proteins are enriched in caveolae (Chen-Izu et al., 2000). The different localization of $\beta \mathrm{AR}$ subtypes has implications for cell death responses that occur in heart failure: $\beta_{1} \mathrm{AR}$ stimulation can promote myocyte apoptosis, whereas $\beta_{2} \mathrm{AR}$ activation can be antiapoptotic via a $\mathrm{G}_{\mathrm{i}^{-}}$, phosphoinositide 3-kinase (PI3K)-, or Akt-dependent pathway (Communal et al., 1999; Xiao et al., 2004).

$\beta_{2} \mathrm{ARs}$ within caveolae localize to transverse ( $\mathrm{T}$ )-tubules and produce localized cAMP signals in cardiac myocytes (Head et al., 2005; Nikolaev et al., 2010). T-tubules are enriched in cholesterol and Cav-3 molecules that characterize caveolar microdomains (Carozzi et al., 2000). The loss of T-tubule structure probably contributes to progression of heart failure and changes in subcellular distribution of $\beta \mathrm{ARs}$ and their signaling components (Wei et al., 2010). With the development of heart failure, the restricted localization of $\beta_{2} \mathrm{ARs}$ in T-tubules can be disrupted, such that $\beta_{2} \mathrm{ARs}$ are found on the myocyte plasma membrane where $\beta_{1} \mathrm{ARs}$ are normally the dominant $\beta \mathrm{AR}$ subtype. As a result, $\beta_{2} \mathrm{ARs}$ can then produce a 
diffuse cAMP signal that is similar to what occurs with $\beta_{1} \mathrm{AR}$ stimulation and thus may enhance myocyte dysfunction (Nikolaev et al., 2010). Importantly, the abnormal distribution of $\beta \mathrm{ARs}$ in heart failure can be mimicked by chemical disruption of the T-tubule/caveolae microenvironment (Nikolaev et al., 2010).

Cav-3 preferentially interacts with $\beta_{2} \mathrm{ARs}$ versus $\beta_{1} \mathrm{ARs}$ (Steinberg, 2004). Caveolae and caveolins play a key role in organizing and regulating cell signaling pathways, including $\beta$ AR signaling (Patel et al., 2008). Caveolae contain major components of $\beta$-adrenergic signaling, including $\beta A R \mathrm{~s}, \mathrm{G}_{\mathrm{s}}$ and $\mathrm{G}_{\mathrm{i}}$, ACs, G protein-coupled receptor kinases, PKA subunits, and L-type calcium channels (Krajewska and Masłowska, 2004; Balijepalli et al., 2006). Localization of L-type calcium channels to caveolae is essential for their regulation by $\beta_{2} \mathrm{ARS}$ (Balijepalli et al., 2006) and localization of $\beta_{2} \mathrm{ARs}$ to caveolae in association with Cav-3 is critical for localized $\beta_{2} \mathrm{AR}$ signaling in cardiac myocytes: Disruption of caveolae converts $\beta_{2} \mathrm{AR}$ responses to a $\beta_{1} \mathrm{AR}$-like response (Calaghan et al., 2008). Cav-3 knockout mice have a $40 \%$ increase in myocardial cAMP content, suggesting that absence of Cav-3 enhances cAMP synthesis (Augustus et al., 2008a). Other data imply that cAMP synthesis in caveolae is influenced by $\mathrm{G}_{\mathrm{i}}$ signaling with a key role for PI3K and cyclic nucleotide phosphodiesterase (PDE) (Kerfant et al., 2006). PI3K signaling in this response depends on macromolecular complexes within caveolae, and close apposition of the T-tubular membrane (containing caveolae) with the sarcoplasmic reticulum (SR) membrane gives PDE access to the SR compartment. Caveolae and T-tubules share structural and functional similarities; both are enriched in cholesterol and Cav-3, increase the functional surface area of the sarcolemma, and share analogous mechanisms of biogenesis (Carozzi et al., 2000). Cav-3 plays a major role in organizing and maintaining T-tubule structure and function in cardiac myocytes (Ziman et al., 2010). Chronic adrenergic stimulation and heart failure can decrease Cav-3 expression (Yamamoto et al., 1999; RuizHurtado et al., 2007), which may ultimately impact the caveolar structure to alter networks for stress adaptation.

Finally, when considering stress adaptation over a lifetime one must consider the aging heart. Age is an important predictor of mortality linked to cardiovascular disease (Boersma et al., 2000). Protective networks are lost in aged myocytes (Mio et al., 2008). Preclinical studies reveal increased sensitivity and decreased tolerance to I/R injury in the aged heart (Headrick et al., 2003; Willems et al., 2005). Recent studies indicate that the heart may be a central player in dysfunction of peripheral organs such as brain, liver, and kidney, underscoring a key idea: A better functioning heart and the resultant enhancement in tissue perfusion will positively influence multiple organ systems with age-related loss in function, contribute to healthier aging, and perhaps enhance lifespan.

Importantly, a decrease in the expression of cardiac Cav-3 (Kawabe et al., 2001) is observed with age, and aging results in dissociation of Cav-1 and -3 from membrane caveolae (Ratajczak et al., 2003). Although Cav-1 KO mice show a decreased lifespan (Park et al., 2003), it is not clear if this a consequence of the cardiovascular aspects regulated by Cav-1; however, these mice are resistant to cardiac protective stimuli (Patel et al., 2007). Cav-3 KO mice develop a progressive cardiomyopathy (Woodman et al., 2002) and are also resistant to cardiac protective stimuli, (Horikawa et al., 2008) but lifespan does not appear to be impacted. However, there is growing evidence to suggest that Cav-3 may have an impact on the function of the aging heart. Cav-3 and caveolae are reduced with age and may be associated with dysfunctional survival signaling (Peart et al., 2007, 2014). Protein kinase C is critical to cardiac protection and this is largely dependent on trafficking to mitochondria. Recently, Cav-3 was shown to be critical for this transport, and age resulted in reduced mitochondrial Protein kinase C (Kang et al., 2017). Such data indicate the potential survival benefits of caveolin in the heart and a potential molecular target to impact acute, chronic, and lifetime stress.

\section{Brain}

Neurons, Glia, and the Blood-Brain Barrier. Neurons are absent of morphologic caveolae but do possess planar microdomains enriched in cholesterol, glycosphingolipids, and sphingomyelin and express all three caveolin isoforms (Shyng et al., 1994; Head and Insel, 2007). Cav-1 is also expressed in CNS endothelia (Sowa, 2012), pericytes (Virgintino et al., 2002), and astrocytes (Cameron et al., 1997). Within cellular components of the blood-brain barrier (BBB), Cav-1 regulates extracellular matrix proteins that include metalloproteinases (Virgintino et al., 2002) and tight junction proteins, which in turn modulate BBB physiology (Abbott et al., 2006; Gu et al., 2011; Liu et al., 2012; Lakhan et al., 2013; Zhao et al., 2014; Gurnik et al., 2016). Cav-1 has also been shown to be critical in hypoxia-induced astrocyte injury (Xu et al., 2016), which can lead to BBB damage and leakage. Knockdown of Cav-1 using Cav-1 small-interfering (si)RNA exacerbated astrocyte cell damage and impaired cellular glutamate uptake after oxygenglucose deprivation (OGD). In contrast, overexpression of the Cav-1 caveolin scaffolding domain peptide attenuated OGDinduced astrocyte apoptosis via ERK signaling (Xu et al., 2016), thus further demonstrating the importance of Cav-1 in BBB physiology (Gu et al., 2012; Fu et al., 2014).

Cav-1 is expressed in both microglia and astrocytes (Salgado et al., 2012). Cav-1 expression was detected in activated microglia (using kainic acid) in several brain regions, with the highest expression measured after 3 days, implicating a potential role of Cav-1 in microglial activation (Takeuchi et al., 2013). Moreover, work from our group demonstrated that Cav-1 protein was decreased and redistributed from the plasmalemma to cytoplasmic vesicles in inactive microglia, whereas the active (amoeboid-shaped) microglia exhibited increased Cav-1 expression (Niesman et al., 2013). Additional published findings demonstrated that Cav-1 KO mice exhibited significant astroand microgliosis as well as an early aging phenotype in the brain (decreased hippocampal synapses, altered cerebrovascular, and reduced progrowth signaling components) (Head et al., 2010), suggesting that loss of Cav-1 may in part contribute to neuropathological conditions in the brain.

Neuronal Cav-1: Neuroprotective Signaling and Plasticity. Specifically, within neurons, Cav-1 scaffolds and organizes neurotransmitter and neurotrophic receptors $[N$ methyl-D-aspartate receptors (NMDARs) and tropomyosin receptor kinase B (TrkB)] in raft microdomains in vitro (Head et al., 2008, 2011) and in vivo (Mandyam et al., 2017). Knockdown of Cav-1 using small-interfering (si)RNA knockdown blunted NMDAR and TrkB-mediated signaling (Head et al., 2008, 2011). 
Studies employing either a sublethal ischemia- or NMDApreconditioning model increased expression of phosphorylated (P) Cav-1, P-Src, and P-ERK1/2 in primary cortical neurons from rats or mice (Head et al., 2008). Primary neurons treated with Cav-1 small-interfering RNA or isolated from Cav-1 KO mice lacked NMDA-mediated increase in P-Src and P-ERK, as well as sublethal ischemia- and NMDA-induced preconditioning. Cav-1 re-expression (using a viral vector) in Cav-1 KO primary neurons restored NMDA-mediated increase in P-Src and P-ERK1/2 and redistributed NMDAR2B to membrane rafts.

In addition to a neuroprotective role, additional studies have shown that Cav-1 promotes neuronal and synaptic plasticity and improves neurobehavior (Head et al., 2011; Egawa et al., 2017a,b; Mandyam et al., 2017). Using a neuronspecific synapsin promoter to express Cav-1 (termed SynCav1) specifically in neurons, Cav-1 overexpression enhanced cellular cholesterol accumulation and raft formation, augmented receptor-mediated cAMP production, functional NMDAR (P-Src, P-CaMKII, P-ERK1/2) and TrkB signaling (P-TrkB, P-Akt), dendritic growth and arborization in vitro (Head et al., 2011) and in vivo (Mandyam et al., 2017) and prevented hippocampal-dependent learning and memory loss and improved motor function in a murine model of traumatic brain injury (Egawa et al., 2017a). Further work from our group showed that when delivered to the hippocampus in vivo, AAV9-SynCav1 increased hippocampal neuroplasticity, improved fear learning and memory in adult and aged mice (Mandyam et al., 2017), and promoted ultrastructural and functional indicators of synaptic plasticity (Egawa et al., 2017b), suggesting that Cav-1 and raft microdomains alter aspects of synapse biology necessary for functional neuronal and synaptic plasticity.

\section{Eye}

Along with the heart and brain, the eye is an organ sensitive to external stressors and one that shows a clear aging phenotype. The aging eye shows retinal deterioration, macular degeneration, changes in the lens, drainage issues, and many other changes that ultimately lead to declining and failing vision (Salvi et al., 2006). Though studies involving caveolin in the eye have been lagging compared with other organ systems, there is a recent growing interest in studying the relationship of caveolin to the eye ( $\mathrm{Gu}$ et al., 2017). This interest has been fueled by a number of recent studies suggesting Cav-1/Cav-2 as potential glaucoma-susceptible genes in multiple populations (Wiggs et al., 2011; Chen et al., 2014; Loomis et al., 2014; Yoshikawa et al., 2017). Cav-1 has been shown to protect retinal ganglion cells through a survival kinase activation mechanism involving Akt similar to that in the heart (Zhang et al., 2017). This was observed in a stress model involving ocular hypertension-induced injury and suggests Cav-1 as a potential therapeutic target. Studies with pressure overload and hypertension in the heart (Horikawa et al., 2011; Markandeya et al., 2015) suggest the same protection of terminally differentiated cardiac myocytes, with the unique observation that cardiac myocytes and hearts with overexpression do not hypertrophy, whereas wild-type hearts nearly double in size. Such preserved responses in myocytes and neurons suggest a generalized response to hypertensive stress (i.e., physical or receptor initiated stress) with common, as of yet unidentified, downstream signaling that is caveolin-dependent and may be a novel therapeutic target. Further studies using Cav-1 KO mice suggest that Cav$1 /$ caveolae may be mechanoprotective in the eye in response to increased pressure that may be linked to alteration in aqueous humor drainage and is probably dependent on nitric oxide (Elliott et al., 2016; Song et al., 2017). At the cellular level, this mutation probably impacts a variety of cells in the eye, including the trabecular meshwork cells (Aga et al., 2014). Further exploration is needed to confirm a molecular function for caveolin in glaucoma. In addition, a number of studies have linked caveolin to retinal blood-barrier changes (Klaassen et al., 2009; Tian et al., 2012; Gu et al., 2014) that have important implications for primary and secondary diseases related to the eye. As the field grows, it is expected that the eye will present a fruitful target for caveolin modulations as potential therapy for stress adaptation.

\section{Novel Molecular Mechanisms}

Many different domains that have been described for caveolin (i.e., scaffolding domain, oligomerization domain, a number of post-translational modification sites) are implicated in a number of cellular and disease processes (Patel et al., 2008; Patel and Insel, 2009). Studies related to these domains have led to significant insights into caveolin regulation of cell biology. However, detailed mechanistic functions of the C-terminus of Cav-1 are not well described and this area of caveolin research is fairly new but may hold promise for defining novel functions of caveolin. During the last decade, many patients with juvenile pulmonary arterial hypertension and various lipodystrophy phenotypes were identified with C-terminal Cav-1 mutations (Austin et al., 2012; Garg et al., 2015; Schrauwen et al., 2015). Importantly, a heterozygous frameshift mutation that leads to a premature stop codon and truncation at amino acid 160 results in a neonatal progerialike phenotype (Schrauwen et al., 2015). The fibroblasts from this patient show a near complete loss of Cav-1 expression, suggesting an importance for caveolin in regulating "aging" phenotypes in the cell.

The two main functions of the C-terminus were originally described as: 1) membrane attachment (proximal third) and 2) protein/protein interaction (distal third) (Razani et al., 1999; Schlegel and Lisanti, 2000). Mutated caveolin (Cav-1 $\delta \mathrm{C}$ ) proteins show that the C-terminus is required for homooligomers to interact ( $\mathrm{Li}$ et al., 1998). Additionally, functional Cav-1 is required to recruit Cav-2 to the membrane (Li et al., 1998). Furthermore, the Cav-1 C-terminal region has been described as interacting with both the $\mathrm{N}$ - and C-terminal region specifically and is required for homo-oligomerization (Song et al., 1997), and both the $\mathrm{N}$ - and C-terminus interact with eNOS oxygenase domain (Ju et al., 1997). The C-terminal region is important in conjunction with the scaffolding domain to mediate endothelin B signaling (Yamaguchi et al., 2003). A splice variant of caveolin-2 mRNA that was identified lacked the C-terminal region. This variant localized to the endoplasmic reticulum, whereas the full version localized with Cav-1 to the Golgi apparatus and plasma membrane, suggesting an important role for the C-terminus in caveolin localization (Kogo et al., 2002). There appears to be a gap in the literature when it comes to assessing the structure of the C-terminal region, and just recently, the C-terminal secondary structure 
of Cav-1 was described as helical using NMR spectroscopy (Plucinsky and Glover, 2015). C-terminal tagging of ectopically expressed Cav-1 with fluorescence proteins (EGFP, mCherry, and myc) showed enhanced aggregation and/or degradation of a wild-type and mutant form, whereas the endogenous forms remained mainly intact (Han et al., 2015). Antibodies against the C-terminal domain are currently under investigation for inhibiting Cav-1-mediated signaling in cancer cells (Kuo et al., 2012). Taken together, these studies imply a crucial role for the C-terminal region of Cav-1 in signaling, localization, and assembly of caveolin oligomers. Though detailed mechanisms have not been worked out, a description of these C-terminal mutations identify a new region of caveolin, one largely ignored, as a potential hot spot for regulation of cell physiology critical to stress adaptation.

Caveolins can be post-translationally modified, though limited insights exist regarding the physiologic consequence of such modification. Caveolin was originally discovered as a target of Src (Rothberg et al., 1992), which itself is a major stress-regulated kinase. In the heart, studies in Cav-1 knockout mice suggest that Cav-1/Src interactions are critical to adaptation to ischemic stress (Patel et al., 2007) and cell-cell communication and arrhythmogenicity (Yang et al., 2014). Cav-1 tyrosine 14 is the primary Src phosphorylation target that has been implicated in focal adhesion and cancer biology (Ortiz et al., 2016; Meng et al., 2017), endothelial cell signaling in sepsis-induced lung injury (Jiao et al., 2013), regulation of mechanotransduction (Zhang et al., 2007; Joshi et al., 2012), and insulin signaling (Chen et al., 2008). Additionally, caveolins can undergo S-nitrosylation, which is important in the setting of oxidant stress. This may have implications for acute cardiac ischemia (Sun et al., 2015), as well as the structure of caveolin oligomers (Bakhshi et al., 2013) and caveolae in pathophysiology. Limited information exists regarding modifications specific to Cav-3; however, it has been suggested that in addition to S-nitrosylation (Sun et al., 2015), Cav-3 may undergo SUMOylation leading to regulation of GPCR and eNOS signaling (Fuhs and Insel, 2011).

In addition to potential membrane-specific changes related to caveolin, caveolae and caveolin have become important considerations in the regulation of mitochondrial structure and function. Mitochondria, being major regulators of energy homeostasis and regulators of stress signaling in the cell, are a major control point for stress adaptation in the cell. In the heart, caveolae are found in close proximity to mitochondria, and stress induces a transfer of caveolin to the mitochondria, leading to preserved mitochondrial structure and function in response to injury (Fridolfsson et al., 2012). Such an observation was also seen in cancer cells and Caenorhabditis elegans suggesting a potential generalized mechanism of caveolin protection of mitochondria (Fridolfsson et al., 2012). Cav-1 has also been described as a modulator of mitochondrial function (Bosch et al., 2011; Asterholm et al., 2012), wherein decreased Cav-1 expression led to mitochondrial cholesterol accumulation (Bosch et al., 2011) and downregulation of mitochondrial genes (Asterholm et al., 2012).

Recently, it was shown that in Cav- $1^{-/-}$mouse embryonic fibroblasts, cellular senescence, and mitochondrial dysfunction was observed. This was attributed to the p53-p21 pathway and the downregulation of cardiolipin. In regard to mitochondrial function, respiration was decreased with a reduced activity of complex I, inactivated SIRT1, and decreased $\mathrm{NAD}^{+} / \mathrm{NADH}$ ratios (Yu et al., 2017). From a cancer perspective, the influence of Cav-1 on cell metabolism, mitochondrial function, glutaminolysis, fatty acid metabolism, and autophagy has been reviewed (Nwosu et al., 2016). In regard to mitochondrial function, increased Cav-1 levels in tumor cells increased mitochondrial number and respiration, mitochondrial reactive oxygen species, mitochondrial complex I-V, $\mathrm{Ca}^{2+}$-signaling, altered intracellular cholesterol flux, and decreased apoptosis (Nwosu et al., 2016). Furthermore, Cav1 has been attributed roles in maintaining mitochondrial integrity and function in the setting of increased free radicals (Volonte et al., 2016). Knockdown of Cav-1 results in metabolic switching with decreased glycolytic intermediates, increased fatty acids, and autophagy activation (Shiroto et al., 2014). Furthermore, Cav-1 is downregulated in stromal fibroblasts, which leads to accelerated epithelial breast cancer growth. This has been termed reverse Warburg effect or "twocompartment tumor metabolism," in which the stromal fibroblasts supply the tumor cells with metabolites (Salem et al., 2012). Taken together these multiple roles for caveolin in regulating mitochondrial dynamics seem to be a crucial to cell fate and offer multiple sites for possible therapeutic intervention. Nevertheless, the role of caveolin in enddifferentiated cells like cardiac myocytes and neurons is less well described with respect to mitochondrial function and warrants further investigation.

\section{Conclusions}

The study of caveolins/caveolae has come a long way since the early structural description of caveolae over six decades ago. Over this time our understanding has grown dramatically from structure to function with a particular focus on the caveolin proteins. What has emerged is an appreciation that these proteins are indeed critical features of cells and act as regulatory control points for cell adaptation to stress. The role of caveolin proteins is readily apparent in terminally differentiated cells such as cardiac myocytes and neurons, but caveolins have important implications for proliferative cells as well, such as smooth muscle, fibroblast, glia, cancer, and many others. We can learn a lot from mutations in these proteins and their impact on cell biology as well as the regulation of intracellular structures by caveolin. What will likely fuel the next six decades of research on caveolin is the use of cellspecific knowledge that has and will be gathered and the application of targeted therapeutics to modulate caveolin and caveolin-specific pathways in precise ways to modulate disease manifestation and treatment.

\section{Authorship Contributions}

Wrote and contributed to the writing of the manuscript: Schilling, Head, Patel.

\section{References}

Abbott NJ, Rönnbäck L, and Hansson E (2006) Astrocyte-endothelial interactions at the blood-brain barrier. Nat Rev Neurosci 7:41-53.

Abrahams PH, Day A, and Allt G (1980) Schwann cell plasma membrane changes induced by nerve crush. A freeze-fracture study. Acta Neuropathol 50:85-90.

Aga M, Bradley JM, Wanchu R, Yang YF, Acott TS, and Keller KE (2014) Differential effects of caveolin-1 and -2 knockdown on aqueous outflow and altered extracellular matrix turnover in caveolin-silenced trabecular meshwork cells. Invest Ophthalmol Vis Sci 55:5497-5509.

Asterholm IW, Mundy DI, Weng J, Anderson RG, and Scherer PE (2012) Altered mitochondrial function and metabolic inflexibility associated with loss of caveolin1. Cell Metab 15:171-185. 
Augustus AS, Buchanan J, Addya S, Rengo G, Pestell RG, Fortina P, Koch WJ, Bensadoun A, Abel ED, and Lisanti MP (2008a) Substrate uptake and metabolism are preserved in hypertrophic caveolin-3 knockout hearts. Am J Physiol Heart Circ Physiol 295:H657-H666.

Augustus AS, Buchanan J, Gutman E, Rengo G, Pestell RG, Fortina P, Koch WJ, Bensadoun A, Abel ED, and Lisanti MP (2008b) Hearts lacking caveolin-1 develop hypertrophy with normal cardiac substrate metabolism. Cell Cycle 7:2509-2518.

Austin ED, Ma L, LeDuc C, Berman Rosenzweig E, Borczuk A, Phillips JA, III, Palomero T, Sumazin P, Kim HR, Talati MH, et al. (2012) Whole exome sequencing to identify a novel gene (caveolin-1) associated with human pulmonary arterial hypertension. Circ Cardiovasc Genet 5:336-343.

Bakhshi FR, Mao M, Shajahan AN, Piegeler T, Chen Z, Chernaya O, Sharma T, Elliott WM, Szulcek R, Bogaard HJ, et al. (2013) Nitrosation-dependent caveolin 1 phosphorylation, ubiquitination, and degradation and its association with idiopathic pulmonary arterial hypertension. Pulm Circ 3:816-830.

Balijepalli RC, Foell JD, Hall DD, Hell JW, and Kamp TJ (2006) Localization of cardiac L-type $\mathrm{Ca}(2+)$ channels to a caveolar macromolecular signaling complex is required for beta(2)-adrenergic regulation. Proc Natl Acad Sci USA 103 $7500-7505$.

Ballard-Croft C, Locklar AC, Kristo G, and Lasley RD (2006) Regional myocardial ischemia-induced activation of MAPKs is associated with subcellular redistribution of caveolin and cholesterol. Am J Physiol Heart Circ Physiol 291:H658-H667.

Boersma E, Pieper KS, Steyerberg EW, Wilcox RG, Chang W-C, Lee KL, Akkerhuis KM, Harrington RA, Deckers JW, Armstrong PW, et al.; The PURSUIT Investigators (2000) Predictors of outcome in patients with acute coronary syndromes without persistent ST-segment elevation. Results from an international trial of 9461 patients. Circulation 101:2557-2567.

Bosch M, Marí M, Herms A, Fernández A, Fajardo A, Kassan A, Giralt A, Colell A, Balgoma D, Barbero E, et al. (2011) Caveolin-1 deficiency causes cholesteroldependent mitochondrial dysfunction and apoptotic susceptibility. Curr Biol 21: $681-686$.

Calaghan S, Kozera L, and White E (2008) Compartmentalisation of cAMPdependent signalling by caveolae in the adult cardiac myocyte. $J$ Mol Cell Cardiol 45:88-92.

Calebiro D, Nikolaev VO, Gagliani MC, de Filippis T, Dees C, Tacchetti C, Persani L, and Lohse MJ (2009) Persistent cAMP-signals triggered by internalized G-proteincoupled receptors. PLoS Biol 7:e1000172.

Cameron PL, Ruffin JW, Bollag R, Rasmussen H, and Cameron RS (1997) Identification of caveolin and caveolin-related proteins in the brain. $J$ Neurosci 17: 9520-9535.

Capozza F, Combs TP, Cohen AW, Cho YR, Park SY, Schubert W, Williams TM, Brasaemle DL, Jelicks LA, Scherer PE, et al. (2005) Caveolin-3 knockout mice show increased adiposity and whole body insulin resistance, with ligand-induced insulin receptor instability in skeletal muscle. Am J Physiol Cell Physiol 288: C1317-C1331.

Carozzi AJ, Ikonen E, Lindsay MR, and Parton RG (2000) Role of cholesterol in developing T-tubules: analogous mechanisms for T-tubule and caveolae biogenesis. Traffic 1:326-341.

Chen F, Klein AP, Klein BE, Lee KE, Truitt B, Klein R, Iyengar SK, and Duggal P (2014) Exome array analysis identifies CAV1/CAV2 as a susceptibility locus for intraocular pressure. Invest Ophthalmol Vis Sci 56:544-551.

Chen J, Capozza F, Wu A, Deangelis T, Sun H, Lisanti M, and Baserga R (2008) Regulation of insulin receptor substrate-1 expression levels by caveolin-1. J Cell Physiol 217:281-289.

Chen-Izu Y, Xiao RP, Izu LT, Cheng H, Kuschel M, Spurgeon H, and Lakatta EG (2000) G(i)-dependent localization of beta(2)-adrenergic receptor signaling to L-type $\mathrm{Ca}(2+)$ channels. Biophys $J$ 79:2547-2556.

Cohen AW, Park DS, Woodman SE, Williams TM, Chandra M, Shirani J, Pereira de Souza A, Kitsis RN, Russell RG, Weiss LM, et al. (2003) Caveolin-1 null mice develop cardiac hypertrophy with hyperactivation of p42/44 MAP kinase in cardiac fibroblasts. Am J Physiol Cell Physiol 284:C457-C474.

Communal C, Singh K, Sawyer DB, and Colucci WS (1999) Opposing effects of beta(1)- and beta(2)-adrenergic receptors on cardiac myocyte apoptosis : role of a pertussis toxin-sensitive G protein. Circulation 100:2210-2212.

Costello BR and Shafiq SA (1979) Freeze-fracture study of muscle plasmalemma in normal and dystrophic chickens. Muscle Nerve 2:191-201.

Dorn GW, II (2010) Medicine. Refugee receptors switch sides. Science 327:1586-1587.

Dorn GW, II and Liggett SB (2009) Mechanisms of pharmacogenomic effects of genetic variation within the cardiac adrenergic network in heart failure. Mol Pharmacol 76:466-480.

Egawa J, Schilling JM, Cui W, Posadas E, Sawada A, Alas B, Zemljic-Harpf AE, Fannon-Pavlich MJ, Mandyam CD, Roth DM, et al. (2017a) Neuron-specific caveolin-1 overexpression improves motor function and preserves memory in mice subjected to brain trauma. FASEB $J$ 31:3403-3411.

Egawa J, Zemljic-Harpf A, Mandyam CD, Niesman IR, Lysenko LV, Kleschevnikov AM, Roth DM, Patel HH, Patel PM, and Head BP (2017b) Neuron-targeted caveolin-1 promotes ultrastructural and functional hippocampal synaptic plasticity. Cereb Cortex Jul 31: 1-12. (published ahead of print).

Elliott MH, Ashpole NE, Gu X, Herrnberger L, McClellan ME, Griffith GL, Reagan AM Boyce TM, Tanito M, Tamm ER, et al. (2016) Caveolin-1 modulates intraocular pressure: implications for caveolae mechanoprotection in glaucoma. Sci Rep 6:37127.

Fernandez-Rojo MA and Ramm GA (2016) Caveolin-1 function in liver physiology and disease. Trends Mol Med 22:889-904.

Frank JS, Beydler S, Kreman M, and Rau EE (1980) Structure of the freeze-fractured sarcolemma in the normal and anoxic rabbit myocardium. Circ Res 47:131-143.

Fridolfsson HN, Kawaraguchi Y, Ali SS, Panneerselvam M, Niesman IR, Finley JC, Kellerhals SE, Migita MY, Okada H, Moreno AL, et al. (2012) Mitochondrialocalized caveolin in adaptation to cellular stress and injury. FASEB $J \mathbf{2 6}$ : 4637-4649.
Fu S, Gu Y, Jiang JQ, Chen X, Xu M, Chen X, and Shen J (2014) Calycosin-7-O- $\beta$-Dglucoside regulates nitric oxide/caveolin-1/matrix metalloproteinases pathway and protects blood-brain barrier integrity in experimental cerebral ischemiareperfusion injury. J Ethnopharmacol 155:692-701.

Fuhs SR and Insel PA (2011) Caveolin-3 undergoes SUMOylation by the SUMO E3 ligase PIASy: sumoylation affects G-protein-coupled receptor desensitization. $J$ Biol Chem 286:14830-14841.

Gabella G (1978) Inpocketings of the cell membrane (caveolae) in the rat myocardium. J Ultrastruct Res 65:135-147.

Gabella G and Blundell D (1978) Effect of stretch and contraction on caveolae of smooth muscle cells. Cell Tissue Res 190:255-271.

Galbiati F, Engelman JA, Volonte D, Zhang XL, Minetti C, Li M, Hou H, Jr, Kneitz B, Edelmann W, and Lisanti MP (2001) Caveolin-3 null mice show a loss of caveolae, changes in the microdomain distribution of the dystrophin-glycoprotein complex, and t-tubule abnormalities. J Biol Chem 276:21425-21433.

Garg A, Kircher M, Del Campo M, Amato RS, and Agarwal AK; University of Washington Center for Mendelian Genomics (2015) Whole exome sequencing identifies de novo heterozygous CAV1 mutations associated with a novel neonata onset lipodystrophy syndrome. Am J Med Genet A 167A:1796-1806.

Gu X, Fliesler SJ, Zhao YY, Stallcup WB, Cohen AW, and Elliott MH (2014) Loss of caveolin-1 causes blood-retinal barrier breakdown, venous enlargement, and mural cell alteration. Am J Pathol 184:541-555.

Gu X, Reagan AM, McClellan ME, and Elliott MH (2017) Caveolins and caveolae in ocular physiology and pathophysiology. Prog Retin Eye Res 56:84-106.

$\mathrm{Gu}$ Y, Dee CM, and Shen J (2011) Interaction of free radicals, matrix metalloproteinases and caveolin-1 impacts blood-brain barrier permeability. Front Biosci (Schol Ed) 3:1216-1231.

Gu Y, Zheng G, Xu M, Li Y, Chen X, Zhu W, Tong Y, Chung SK, Liu KJ, and Shen J (2012) Caveolin-1 regulates nitric oxide-mediated matrix metalloproteinases activity and blood-brain barrier permeability in focal cerebral ischemia and reperfusion injury. $J$ Neurochem 120:147-156.

Gurnik S, Devraj K, Macas J, Yamaji M, Starke J, Scholz A, Sommer K, Di Tacchio M, Vutukuri R, Beck H, et al. (2016) Angiopoietin-2-induced blood-brain barrier compromise and increased stroke size are rescued by VE-PTP-dependent restoration of Tie2 signaling. Acta Neuropathol 131:753-773.

Han B, Tiwari A, and Kenworthy AK (2015) Tagging strategies strongly affect the fate of overexpressed caveolin-1. Traffic 16:417-438.

Han YS, Arroyo J, and Ogut O (2013) Human heart failure is accompanied by altered protein kinase A subunit expression and post-translational state. Arch Biochem Biophys 538:25-33.

Hausenloy DJ, Tsang A, and Yellon DM (2005) The reperfusion injury salvage kinase pathway: a common target for both ischemic preconditioning and postconditioning. Trends Cardiovasc Med 15:69-75.

Head BP, Hu Y, Finley JC, Saldana MD, Bonds JA, Miyanohara A, Niesman IR, Ali SS, Murray F, Insel PA, et al. (2011) Neuron-targeted caveolin-1 protein enhances signaling and promotes arborization of primary neurons. $J$ Biol Chem $\mathbf{2 8 6}$ 33310-33321.

Head BP and Insel PA (2007) Do caveolins regulate cells by actions outside of caveolae? Trends Cell Biol 17:51-57.

Head BP, Patel HH, Roth DM, Lai NC, Niesman IR, Farquhar MG, and Insel PA (2005) G-protein-coupled receptor signaling components localize in both sarcolemmal and intracellular caveolin-3-associated microdomains in adult cardiac myocytes. J Biol Chem 280:31036-31044.

Head BP, Patel HH, Tsutsumi YM, Hu Y, Mejia T, Mora RC, Insel PA, Roth DM, Drummond JC, and Patel PM (2008) Caveolin-1 expression is essential for N-methyl-D-aspartate receptor-mediated Src and extracellular signal-regulated kinase $1 / 2$ activation and protection of primary neurons from ischemic cell death. FASEB J 22:828-840.

Head BP, Peart JN, Panneerselvam M, Yokoyama T, Pearn ML, Niesman IR, Bonds JA, Schilling JM, Miyanohara A, Headrick J, et al. (2010) Loss of caveolin-1 accelerates neurodegeneration and aging. PLoS One 5:e15697.

Headrick JP, Willems L, Ashton KJ, Holmgren K, Peart J, and Matherne GP (2003) Ischaemic tolerance in aged mouse myocardium: the role of adenosine and effects of A1 adenosine receptor overexpression. J Physiol 549:823-833.

Horikawa YT, Panneerselvam M, Kawaraguchi Y, Tsutsumi YM, Ali SS, Balijepalli RC, Murray F, Head BP, Niesman IR, Rieg T, et al. (2011) Cardiac-specific overexpression of caveolin-3 attenuates cardiac hypertrophy and increases natriuretic peptide expression and signaling. J Am Coll Cardiol 57:2273-2283.

Horikawa YT, Patel HH, Tsutsumi YM, Jennings MM, Kidd MW, Hagiwara Y, Ishikawa Y, Insel PA, and Roth DM (2008) Caveolin-3 expression and caveolae are required for isoflurane-induced cardiac protection from hypoxia and ischemia/ reperfusion injury. J Mol Cell Cardiol 44:123-130.

Insel PA and Patel HH (2007) Do studies in caveolin-knockouts teach us about physiology and pharmacology or instead, the ways mice compensate for 'lost proteins'? Br J Pharmacol 150:251-254.

Jiao H, Zhang Y, Yan Z, Wang ZG, Liu G, Minshall RD, Malik AB, and Hu G (2013) Caveolin-1 Tyr14 phosphorylation induces interaction with TLR4 in endothelial cells and mediates MyD88-dependent signaling and sepsis-induced lung inflammation. J Immunol 191:6191-6199.

Jin Y, Lee SJ, Minshall RD, and Choi AM (2011) Caveolin-1: a critical regulator of lung injury. Am J Physiol Lung Cell Mol Physiol 300:L151-L160.

Joshi B, Bastiani M, Strugnell SS, Boscher C, Parton RG, and Nabi IR (2012) Phosphocaveolin-1 is a mechanotransducer that induces caveola biogenesis via Egr1 transcriptional regulation. J Cell Biol 199:425-435.

Ju H, Zou R, Venema VJ, and Venema RC (1997) Direct interaction of endothelial nitric-oxide synthase and caveolin-1 inhibits synthase activity. $J$ Biol Chem 272: 18522-18525.

Kamal FA, Travers JG, and Blaxall BC (2012) G protein-coupled receptor kinases in cardiovascular disease: why "where" matters. Trends Cardiovasc Med 22:213-219. 
Kang C, Qin J, Osei W, and Hu K (2017) Regulation of protein kinase C-epsilon and its age-dependence. Biochem Biophys Res Commun 482:1201-1206.

Kawabe JI, Grant BS, Yamamoto M, Schwencke C, Okumura S, and Ishikawa Y (2001) Changes in caveolin subtype protein expression in aging rat organs. Mol Cell Endocrinol 176:91-95.

Kerfant BG, Rose RA, Sun H, and Backx PH (2006) Phosphoinositide 3-kinase gamma regulates cardiac contractility by locally controlling cyclic adenosine monophosphate levels. Trends Cardiovasc Med 16:250-256.

Klaassen I, Hughes JM, Vogels IM, Schalkwijk CG, Van Noorden CJ, and Schlingemann RO (2009) Altered expression of genes related to blood-retina barrier disruption in streptozotocin-induced diabetes. Exp Eye Res 89:4-15.

Koga A, Oka N, Kikuchi T, Miyazaki H, Kato S, and Imaizumi T (2003) Adenovirusmediated overexpression of caveolin-3 inhibits rat cardiomyocyte hypertrophy. Hypertension 42:213-219.

Kogo H, Ishiguro K, Kuwaki S, and Fujimoto T (2002) Identification of a splice variant of mouse caveolin-2 mRNA encoding an isoform lacking the C-terminal domain. Arch Biochem Biophys 401:108-114.

Koneru S, Penumathsa SV, Thirunavukkarasu M, Samuel SM, Zhan L, Han Z, Maulik G, Das DK, and Maulik N (2007) Redox regulation of ischemic preconditioning is mediated by the differential activation of caveolins and their association with eNOS and GLUT-4. Am J Physiol Heart Circ Physiol 292 H2060-H2072.

Kordylewski L, Goings GE, and Page E (1993) Rat atrial myocyte plasmalemmal caveolae in situ. Reversible experimental increases in caveolar size and in surface density of caveolar necks. Circ Res 73:135-146.

Krajewska WM and Masłowska I (2004) Caveolins: structure and function in signal transduction. Cell Mol Biol Lett 9:195-220.

Kuo SR, Tahir SA, Park S, Thompson TC, Coffield S, Frankel AE, and Liu JS (2012) Anti-caveolin-1 antibodies as anti-prostate cancer therapeutics. Hybridoma (Larchmt) 31:77-86.

Lakhan SE, Kirchgessner A, Tepper D, and Leonard A (2013) Matrix metalloproteinases and blood-brain barrier disruption in acute ischemic stroke. Front Neurol 4:32.

Li S, Galbiati F, Volonte D, Sargiacomo M, Engelman JA, Das K, Scherer PE and Lisanti MP (1998) Mutational analysis of caveolin-induced vesicle formation Expression of caveolin-1 recruits caveolin-2 to caveolae membranes. FEBS Lett 434:127-134

Liu J, Jin X, Liu KJ, and Liu W (2012) Matrix metalloproteinase-2-mediated occludin degradation and caveolin-1-mediated claudin-5 redistribution contribute to bloodbrain barrier damage in early ischemic stroke stage. J Neurosci 32:3044-3057.

Lloyd-Jones D, Adams R, Carnethon M, De Simone G, Ferguson TB, Flegal K, Ford E, Furie K, Go A, Greenlund K, et al ; American Heart Association Statistics Committee and Stroke Statistics Subcommittee (2009) Heart disease and stroke statistics-2009 update: a report from the American Heart Association Statistics Committee and Stroke Statistics Subcommittee. Circulation 119:480-486.

Loomis SJ, Kang JH, Weinreb RN, Yaspan BL, Cooke Bailey JN, Gaasterland D, Gaasterland T, Lee RK, Lichter PR, Budenz DL, et al. (2014) Association of CAV1/ CAV2 genomic variants with primary open-angle glaucoma overall and by gender and pattern of visual field loss. Ophthalmology 121:508-516.

Macdougall DA, Agarwal SR, Stopford EA, Chu H, Collins JA, Longster AL, Colyer J, Harvey RD, and Calaghan S (2012) Caveolae compartmentalise $\beta 2$-adrenoceptor signals by curtailing cAMP production and maintaining phosphatase activity in the sarcoplasmic reticulum of the adult ventricular myocyte. J Mol Cell Cardiol $\mathbf{5 2}$ 388-400.

Mandyam CD, Schilling JM, Cui W, Egawa J, Niesman IR, Kellerhals SE, Staples MC, Busija AR, Risbrough VB, Posadas E, et al. (2017) Neuron-targeted caveolin-1 improves molecular signaling, plasticity, and behavior dependent on the hippocampus in adult and aged mice. Biol Psychiatry 81:101-110.

Maniatis NA, Chernaya O, Shinin V, and Minshall RD (2012) Caveolins and lung function. Adv Exp Med Biol 729:157-179.

Markandeya YS, Phelan LJ, Woon MT, Keefe AM, Reynolds CR, August BK, Hacker TA, Roth DM, Patel HH, and Balijepalli RC (2015) Caveolin-3 overexpression attenuates cardiac hypertrophy via inhibition of T-type $\mathrm{Ca}^{2+}$ current modulated by protein kinase $\mathrm{C} \alpha$ in cardiomyocytes. $J$ Biol Chem 290:22085-22100.

Maurice P, Benleulmi-Chaachoua A, and Jockers R (2012) Differential assembly of GPCR signaling complexes determines signaling specificity. Subcell Biochem $\mathbf{6 3}$ $225-240$.

Meng F, Saxena S, Liu Y, Joshi B, Wong TH, Shankar J, Foster LJ, Bernatchez P, and Nabi IR (2017) The phospho-caveolin-1 scaffolding domain dampens force fluctuations in focal adhesions and promotes cancer cell migration. Mol Biol Cell 28:2190-2201.

Mio Y, Bienengraeber MW, Marinovic J, Gutterman DD, Rakic M, Bosnjak ZJ, and Stadnicka A (2008) Age-related attenuation of isoflurane preconditioning in human atrial cardiomyocytes: roles for mitochondrial respiration and sarcolemmal adenosine triphosphate-sensitive potassium channel activity. Anesthesiology 108: $612-620$

Mugnaini E, Osen KK, Schnapp B, and Friedrich VL, Jr (1977) Distribution of Schwann cell cytoplasm and plasmalemmal vesicles (caveolae) in peripheral myelin sheaths. An electron microscopic study with thin sections and freeze-fracturing. $J$ Neurocytol 6:647-668.

Murata T, Lin MI, Huang Y, Yu J, Bauer PM, Giordano FJ, and Sessa WC (2007) Reexpression of caveolin-1 in endothelium rescues the vascular, cardiac, and pulmonary defects in global caveolin-1 knockout mice. J Exp Med 204:2373-2382.

Murry CE, Jennings RB, and Reimer KA (1986) Preconditioning with ischemia: a delay of lethal cell injury in ischemic myocardium. Circulation 74:1124-1136.

Niesman IR, Zemke N, Fridolfsson HN, Haushalter KJ, Levy K, Grove A, Schnoor R, Finley JC, Patel PM, Roth DM, et al. (2013) Caveolin isoform switching as a molecular, structural, and metabolic regulator of microglia. Mol Cell Neurosci 56 283-297.
Nikolaev VO, Moshkov A, Lyon AR, Miragoli M, Novak P, Paur H, Lohse MJ, Korchev YE, Harding SE, and Gorelik J (2010) Beta2-adrenergic receptor redistribution in heart failure changes cAMP compartmentation. Science 327: $1653-1657$

Nwosu ZC, Ebert MP, Dooley S, and Meyer C (2016) Caveolin-1 in the regulation of cell metabolism: a cancer perspective. Mol Cancer 15:71.

Oguchi K and Tsukagoshi H (1980) An electron-microscopic study of the T-system in progressive muscular dystrophy (Duchenne) using lanthanum. J Neurol Sci 44: $161-168$

Ortiz R, Díaz J, Díaz N, Lobos-Gonzalez L, Cárdenas A, Contreras P, Díaz MI, Otte E, Cooper-White J, Torres V, et al (2016) Extracellular matrix-specific caveolin-1 phosphorylation on tyrosine 14 is linked to augmented melanoma metastasis but not tumorigenesis. Oncotarget 7:40571-40593.

Palade G (1953) Fine structure of blood capillaries. J Appl Physiol 24:1424

Park DS, Cohen AW, Frank PG, Razani B, Lee H, Williams TM, Chandra M, Shirani J, De Souza AP, Tang B, et al. (2003) Caveolin-1 null (-/-) mice show dramatic reductions in life span. Biochemistry 42:15124-15131.

Park DS, Lee H, Frank PG, Razani B, Nguyen AV, Parlow AF, Russell RG, Hulit J, Pestell RG, and Lisanti MP (2002a) Caveolin-1-deficient mice show accelerated mammary gland development during pregnancy, premature lactation, and hyperactivation of the Jak-2/STAT5a signaling cascade. Mol Biol Cell 13:3416-3430.

Park DS, Woodman SE, Schubert W, Cohen AW, Frank PG, Chandra M, Shirani J, Razani B, Tang B, Jelicks LA, et al. (2002b) Caveolin-1/3 double-knockout mice are viable, but lack both muscle and non-muscle caveolae, and develop a severe cardiomyopathic phenotype. Am J Pathol 160:2207-2217.

Parton RG, Joggerst B, and Simons K (1994) Regulated internalization of caveolae. J Cell Biol 127:1199-1215.

Patel HH, Head BP, Petersen HN, Niesman IR, Huang D, Gross GJ, Insel PA, and Roth DM (2006) Protection of adult rat cardiac myocytes from ischemic cell death: role of caveolar microdomains and delta-opioid receptors. Am J Physiol Heart Circ Physiol 291:H344-H350.

Patel HH and Insel PA (2009) Lipid rafts and caveolae and their role in compartmentation of redox signaling. Antioxid Redox Signal 11:1357-1372.

Patel HH, Murray F, and Insel PA (2008) Caveolae as organizers of pharmacologically relevant signal transduction molecules. Annu Rev Pharmacol Toxicol 48: 359-391.

Patel HH, Tsutsumi YM, Head BP, Niesman IR, Jennings M, Horikawa Y, Huang D, Moreno AL, Patel PM, Insel PA, et al. (2007) Mechanisms of cardiac protection from ischemia/reperfusion injury: a role for caveolae and caveolin-1. FASEB $J \mathbf{2 1}$ : 1565-1574.

Peart JN, Gross ER, Headrick JP, and Gross GJ (2007) Impaired p38 MAPK/HSP27 signaling underlies aging-related failure in opioid-mediated cardioprotection. J Mol Cell Cardiol 42:972-980.

Peart JN, Pepe S, Reichelt ME, Beckett N, See Hoe L, Ozberk V, Niesman IR, Patel $\mathrm{HH}$, and Headrick JP (2014) Dysfunctional survival-signaling and stressintolerance in aged murine and human myocardium. Exp Gerontol 50:72-81.

Pereira L, Cheng H, Lao DH, Na L, van Oort RJ, Brown JH, Wehrens XH, Chen J, and Bers DM (2013) Epac2 mediates cardiac $\beta 1$-adrenergic-dependent sarcoplasmic reticulum $\mathrm{Ca}^{2+}$ leak and arrhythmia. Circulation 127:913-922.

Plucinsky SM and Glover KJ (2015) Secondary structure analysis of a functional construct of caveolin-1 reveals a long C-terminal helix. Biophys $J$ 109:1686-1688

Ratajczak P, Damy T, Heymes C, Oliviéro P, Marotte F, Robidel E, Sercombe R, Boczkowski J, Rappaport L, and Samuel JL (2003) Caveolin-1 and -3 dissociations from caveolae to cytosol in the heart during aging and after myocardial infarction in rat. Cardiovasc Res 57:358-369.

Razani B, Engelman JA, Wang XB, Schubert W, Zhang XL, Marks CB, Macaluso F, Russell RG, Li M, Pestell RG, et al. (2001) Caveolin-1 null mice are viable but show evidence of hyperproliferative and vascular abnormalities. J Biol Chem 276: 38121-38138.

Razani B, Rubin CS, and Lisanti MP (1999) Regulation of cAMP-mediated signal transduction via interaction of caveolins with the catalytic subunit of protein kinase A. J Biol Chem 274:26353-26360.

Razani B, Wang XB, Engelman JA, Battista M, Lagaud G, Zhang XL, Kneitz B, Hou H, Jr, Christ GJ, Edelmann W, et al. (2002) Caveolin-2-deficient mice show evidence of severe pulmonary dysfunction without disruption of caveolae. Mol Cell Biol 22:2329-2344.

Rothberg KG, Heuser JE, Donzell WC, Ying YS, Glenney JR, and Anderson RG (1992) Caveolin, a protein component of caveolae membrane coats. Cell 68 673-682.

Royce SG and Le Saux CJ (2014) Role of caveolin-1 in asthma and chronic inflammatory respiratory diseases. Expert Rev Respir Med 8:339-347.

Ruiz-Hurtado G, Fernández-Velasco M, Mourelle M, and Delgado C (2007) LA419, a novel nitric oxide donor, prevents pathological cardiac remodeling in pressureoverloaded rats via endothelial nitric oxide synthase pathway regulation. Hypertension 50:1049-1056.

Sage MD and Jennings RB (1988) Myocyte swelling and plasmalemmal integrity during early experimental myocardial ischemia in vivo. Scanning Microsc 2: 477-484.

Sakata N, Ida T, Joshita T, and Ooneda G (1983) Scanning and transmission electron microscopic study on the cerebral arterial endothelium of experimentally hypertensive rats fed an atherogenic diet. Acta Pathol Jpn 33:1105-1113.

Salem AF, Whitaker-Menezes D, Lin Z, Martinez-Outschoorn UE, Tanowitz HB, Al-Zoubi MS, Howell A, Pestell RG, Sotgia F, and Lisanti MP (2012) Twocompartment tumor metabolism: autophagy in the tumor microenvironment and oxidative mitochondrial metabolism (OXPHOS) in cancer cells. Cell Cycle 11: $2545-2556$

Salgado IK, Serrano M, García JO, Martínez NA, Maldonado HM, Báez-Pagán CA, Lasalde-Dominicci JA, and Silva WI (2012) SorLA in glia: shared subcellular distribution patterns with caveolin-1. Cell Mol Neurobiol 32:409-421. 
Salvi SM, Akhtar S, and Currie Z (2006) Ageing changes in the eye. Postgrad Med $J$ 82:581-587.

Schlegel A and Lisanti MP (2000) A molecular dissection of caveolin-1 membrane attachment and oligomerization. Two separate regions of the caveolin-1 C-terminal domain mediate membrane binding and oligomer/oligomer interactions in vivo. $J$ Biol Chem 275:21605-21617.

Schrauwen I, Szelinger S, Siniard AL, Kurdoglu A, Corneveaux JJ, Malenica I, Richholt R, Van Camp G, De Both M, Swaminathan S, et al. (2015) A frame-shift mutation in CAV1 is associated with a severe neonatal progeroid and lipodystrophy syndrome. PLoS One 10:e131797.

See Hoe LE, Schilling JM, Tarbit E, Kiessling CJ, Busija AR, Niesman IR, Du Toit E, Ashton KJ, Roth DM, Headrick JP, et al. (2014) Sarcolemmal cholesterol and caveolin-3 dependence of cardiac function, ischemic tolerance, and opioidergic cardioprotection. Am J Physiol Heart Circ Physiol 307:H895-H903.

Severs NJ (1981) Plasma membrane cholesterol in myocardial muscle and capillary endothelial cells. Distribution of filipin-induced deformations in freeze-fracture. Eur J Cell Biol 25:289-299.

Shiroto T, Romero N, Sugiyama T, Sartoretto JL, Kalwa H, Yan Z, Shimokawa H, and Michel T (2014) Caveolin-1 is a critical determinant of autophagy, metabolic switching, and oxidative stress in vascular endothelium. PLoS One 9:e87871.

Shyng SL, Heuser JE, and Harris DA (1994) A glycolipid-anchored prion protein is endocytosed via clathrin-coated pits. J Cell Biol 125:1239-1250.

Song JH, Kim M, Park SW, Chen SW, Pitson SM, and Lee HT (2010) Isoflurane via TGF-beta1 release increases caveolae formation and organizes sphingosine kinase signaling in renal proximal tubules. Am J Physiol Renal Physiol 298:F1041-F1050.

Song KS, Tang Z, Li S, and Lisanti MP (1997) Mutational analysis of the properties of caveolin-1. A novel role for the C-terminal domain in mediating homo-typic caveolin-caveolin interactions. J Biol Chem 272:4398-4403.

Song M, Wu J, Lei Y, and Sun X (2017) Genetic deletion of the NOS3 gene in CAV1-/ mice restores aqueous humor outflow function. Invest Ophthalmol Vis Sci 58: $4976-4987$.

Sowa G (2012) Regulation of cell signaling and function by endothelial caveolins: implications in disease. Transl Med (Sunnyvale) (Suppl 8) DOI: 10.4172/2161-1025.S8001.

Steinberg SF (2004) beta(2)-Adrenergic receptor signaling complexes in cardiomyocyte caveolae/lipid rafts. J Mol Cell Cardiol 37:407-415.

Sun J, Nguyen T, Aponte AM, Menazza S, Kohr MJ, Roth DM, Patel HH, Murphy E, and Steenbergen C (2015) Ischaemic preconditioning preferentially increases protein S-nitrosylation in subsarcolemmal mitochondria. Cardiovasc Res 106:227-236.

Takeuchi S, Matsuda W, Tooyama I, and Yasuhara O (2013) Kainic acid induces expression of caveolin-1 in activated microglia in rat brain. Folia Histochem Cytobiol 51:25-30.

Thompson MA, Prakash YS, and Pabelick CM (2014) The role of caveolae in the pathophysiology of lung diseases. Expert Rev Respir Med 8:111-122.

Tian XF, Xia XB, Xu HZ, Xiong SQ, and Jiang J (2012) Caveolin-1 expression regulates blood-retinal barrier permeability and retinal neovascularization in oxygeninduced retinopathy. Clin Experiment Ophthalmol 40:e58-e66.

Timme TL, Goltsov A, Tahir S, Li L, Wang J, Ren C, Johnston RN, and Thompson TC (2000) Caveolin-1 is regulated by c-myc and suppresses c-myc-induced apoptosis. Oncogene 19:3256-3265.

Timofeyev V, Myers RE, Kim HJ, Woltz RL, Sirish P, Heiserman JP, Li N, Singapuri A, Tang T, Yarov-Yarovoy V, et al. (2013) Adenylyl cyclase subtype-specific compartmentalization: differential regulation of L-type $\mathrm{Ca} 2+$ current in ventricular myocytes. Circ Res 112:1567-1576.

Triposkiadis F, Karayannis G, Giamouzis G, Skoularigis J, Louridas G, and Butler J (2009) The sympathetic nervous system in heart failure physiology, pathophysiology, and clinical implications. J Am Coll Cardiol 54:1747-1762.

Tsutsumi YM, Horikawa YT, Jennings MM, Kidd MW, Niesman IR, Yokoyama U, Head BP, Hagiwara Y, Ishikawa Y, Miyanohara A, et al. (2008) Cardiac-specific overexpression of caveolin-3 induces endogenous cardiac protection by mimicking ischemic preconditioning. Circulation 118:1979-1988.

Tsutsumi YM, Kawaraguchi Y, Niesman IR, Patel HH, and Roth DM (2010) Opioid-induced preconditioning is dependent on caveolin-3 expression. Anesth Analg 111:1117-1121.

Virgintino D, Robertson D, Errede M, Benagiano V, Tauer U, Roncali L, and Bertossi M (2002) Expression of caveolin-1 in human brain microvessels. Neuroscience 115 $145-152$.
Volonte D, Liu Z, Shiva S, and Galbiati F (2016) Caveolin-1 controls mitochondrial function through regulation of m-AAA mitochondrial protease. Aging (Albany NY) 8:2355-2369.

Wei S, Guo A, Chen B, Kutschke W, Xie Y-P, Zimmerman K, Weiss RM, Anderson ME, Cheng H, and Song L-S (2010) T-tubule remodeling during transition from hypertrophy to heart failure. Circ Res 107:520-531.

Wiggs JL, Kang JH, Yaspan BL, Mirel DB, Laurie C, Crenshaw A, Brodeur W, Gogarten S, Olson LM, Abdrabou W, et al.; GENEVA Consortium (2011) Common variants near CAV1 and CAV2 are associated with primary open-angle glaucoma in Caucasians from the USA. Hum Mol Genet 20:4707-4713.

Willems L, Zatta A, Holmgren K, Ashton KJ, and Headrick JP (2005) Age-related changes in ischemic tolerance in male and female mouse hearts. $J \mathrm{Mol}$ Cell Cardiol 38:245-256.

Williams TM and Lisanti MP (2004) The caveolin genes: from cell biology to medicine. Ann Med 36:584-595.

Woodman SE, Park DS, Cohen AW, Cheung MW, Chandra M, Shirani J, Tang B, Jelicks LA, Kitsis RN, Christ GJ, et al. (2002) Caveolin-3 knock-out mice develop a progressive cardiomyopathy and show hyperactivation of the p42/44 MAPK cascade. J Biol Chem 277:38988-38997.

Xiang Y and Kobilka B (2003) The PDZ-binding motif of the beta2-adrenoceptor is essential for physiologic signaling and trafficking in cardiac myocytes. Proc Natl Acad Sci USA 100:10776-10781.

Xiao RP, Zhu W, Zheng M, Chakir K, Bond R, Lakatta EG, and Cheng H (2004) Subtype-specific beta-adrenoceptor signaling pathways in the heart and their potential clinical implications. Trends Pharmacol Sci 25:358-365.

Xu L, Wang L, Wen Z, Wu L, Jiang Y, Yang L, Xiao L, Xie Y, Ma M, Zhu W, et al. (2016) Caveolin-1 is a checkpoint regulator in hypoxia-induced astrocyte apoptosis via Ras/Raf/ERK pathway. Am J Physiol Cell Physiol 310:C903-C910.

Yamada E (1955) The fine structure of the gall bladder epithelium of the mouse. $J$ Biophys Biochem Cytol 1:445-458.

Yamaguchi T, Murata Y, Fujiyoshi Y, and Doi T (2003) Regulated interaction of endothelin B receptor with caveolin-1. Eur J Biochem 270:1816-1827.

Yamamoto M, Okumura S, Oka N, Schwencke C, and Ishikawa Y (1999) Downregulation of caveolin expression by cAMP signal. Life Sci 64:1349-1357.

Yang KC, Rutledge CA, Mao M, Bakhshi FR, Xie A, Liu H, Bonini MG, Patel HH, Minshall RD, and Dudley SC, Jr (2014) Caveolin-1 modulates cardiac gap junction homeostasis and arrhythmogenecity by regulating cSrc tyrosine kinase. Circ Arrhythm Electrophysiol 7:701-710.

Yoshikawa M, Nakanishi H, Yamashiro K, Miyake M, Akagi T, Gotoh N, Ikeda HO, Suda K, Yamada H, Hasegawa T, et al.; Nagahama Study Group (2017) Association of glaucoma-susceptible genes to regional circumpapillary retinal nerve fiber layer thickness and visual field defects. Invest Ophthalmol Vis Sci 58:2510-2519.

Yu DM, Jung SH, An HT, Lee S, Hong J, Park JS, Lee H, Lee H, Bahn MS, Lee HC, et al. (2017) Caveolin-1 deficiency induces premature senescence with mitochondrial dysfunction. Aging Cell 16:773-784.

Zhang B, Peng F, Wu D, Ingram AJ, Gao B, and Krepinsky JC (2007) Caveolin-1 phosphorylation is required for stretch-induced EGFR and Akt activation in mesangial cells. Cell Signal 19:1690-1700.

Zhang L, Xu J, Liu R, Chen W, Chen Q, Hu W, Zhou L, Zhang R, Xu H, Lin D, et al. (2017) Caveolin-1 protects retinal ganglion cells against acute ocular hypertension injury via modulating microglial phenotypes and distribution and activating AKT pathway. Sci Rep 7:10716.

Zhao YL, Song JN, and Zhang M (2014) Role of caveolin-1 in the biology of the bloodbrain barrier. Rev Neurosci 25:247-254.

Zhu A, Wei X, Zhang Y, You T, Yao S, Yuan S, Xu H, Li F, and Mao W (2017) Propofol provides cardiac protection by suppressing the proteasome degradation of caveolin3 in ischemic/reperfused rat hearts. J Cardiovasc Pharmacol 69:170-177.

Ziman AP, Gómez-Viquez NL, Bloch RJ, and Lederer WJ (2010) Excitationcontraction coupling changes during postnatal cardiac development. J Mol Cell Cardiol 48:379-386.

Address correspondence to: Dr. Hemal H. Patel, Department of Anesthesiology, UCSD School of Medicine, 9500 Gilman Drive, San Diego, CA. E-mail: hepatel@ucsd.edu 